\title{
TESTING THE PERFORMANCE OF THE INVESTMENT PORTFOLIO USING BLOCK BOOTSTRAP METHOD
}

\author{
Boris Radovanov \\ University of Novi Sad, Faculty of Economics in Subotica, Serbia \\ $\triangle$ radovanovb@ef.uns.ac.rs \\ Aleksandra Marcikić \\ University of Novi Sad, Faculty of Economics in Subotica, Serbia \\ $\bowtie$ amarcikic@ef.uns.ac.rs
}

UDC

336.07

Original

scientific

paper

Received:

13.03.2014

Accepted:

10.07.2014

\begin{abstract}
The aim of this paper is to create a stable model of investment portfolio optimization through a high degree of diversification and reduction of sudden changes in the allocation with monitoring of the dynamics of the impact factor. In this sense, there is bootstrap application procedure, which, without an excessive number of constraints involved in the optimization process provides solutions based on uncertain information. Thus defined, the optimization method has been patented by Michaud (1999) entitled re-sampled efficiency. Accordingly, this paper offers a comparison of the performance block bootstrap optimization models and traditional Markowitz's model inside and outside of the sample by applying the most frequently traded stocks on the BSE. The results show a better performance out of the sample and the presence of a larger number of shares forming the portfolio through bootstrap methodology. However, only through the traditional optimization process could be attained optimum according to the required limits. Such effects can be observed by comparing the limits of efficiency obtained through these optimization models. However, optimization-based methods bootstrap finds its place in reducing errors of assessment resulting from the limited sample size.
\end{abstract}

Keywords: Investment portfolio, optimization, re-sampled efficiency, bootstrap, efficiency limit

\section{Introduction}

Market participants estimate the competitiveness of company registered on financial market by evaluating stock prices. Although this is a time series of unknown and highly volatile daily observations of stock prices in future time, 
the process of constructing investment portfolio under the long-term capital allocation strategy can present the changes comparing a known average.

Considering the effects of market participant behavior on the short-term stock prices movement patterns the market become highly unpredictable or efficient. Nevertheless, long term provides certain evidence of possible success in future forecasting (Fama and French, 1988.). Therefore, the ability of adequate forecasting is available only to long-term oriented investors, while remain elusive the appropriate moment of investment.

One of the preconditions of efficient investing capital allocation is developing a robust methodology which on completely different level considers inherent problems of processing and evaluating data. This includes the integration of optimization process through various methods of resampling data, selection of appropriate financial instruments of investment and technique of time balancing which ensures that selected portfolio stays consistent with dynamic structure of financial market. Proposed methodology possesses all prerequisites for successful implementation in capital allocation decision making, especially in highly volatile financial markets. Actually, chosen bootstrap procedure selectively draws new time series samples of daily returns, but retains the original data structure.

\section{Literature review}

Frequent usage of Markowitz portfolio selection procedure in last couple of decades emphasizes the problem of adequate investment portfolio composition through the extreme weights of individual investment in portfolio, unbalanced capital allocation and absence of sufficient risk diversification. Such an approach, as stated by Becker et al. (2009), increases the effects of estimation errors in calculating investment portfolio weights and decreases out-of-sample performances. How this optimization methodology indicates the high level of sensitivity of all input indicators, a clear intention of creating a reasonable approach appears. This approach determines the result sensitivities to different input parameters and focuses on greater efforts in estimating parameters with lower degrees of sensitivity. There were several attempts of creating model with lower estimation errors and improved portfolio performances. On one side, a technique of portfolio optimization is raised on a higher level by applying the Bayesian approach and Black-Litterman model (Black, Litterman, 1992.). On the other side, the heuristic models have been developed, for example the concept of Michaud (1998) and Michaud and Michaud (2008). This paper includes analysis and application of the resampled efficiency ${ }^{1}$ technique patented by Michaud (1999), which is based on the sampling repetition of daily returns in order to reflect the uncertainty effects in time series.

${ }^{1}$ U.S. Patent \#6,003,018 by Michaud et al., December 19, 1999 
With the aim of analyzing portfolio performances of Michaud's approach, many researches start from a comparison of its results with the results of traditional portfolio selection model. For example, Fletcher and Hillier (2001) found that Michaud's approach outperforms Markowitz model in research of capital market, but those improvements are not statistically significant. Markowitz and Usmen (2003) through the simulation studies found strong evidence of better performances in Michaud's approach then in use of the Bayesian estimation. Some similar observations are achieved by Michaud and Michaud (2008) and Delcourt and Petitjean (2011). However, there is the other side of researches which gives evidence of better performances in Markowitz model. For instance, Harvey et al. (2008) repeated the simulation study made by Markowitz and Usmen (2003) with more sophisticated initial distribution of returns and appropriate estimation algorithm, where superior results mainly appear in Markowitz optimization approach. Furthermore, Becker et al. (2009) confirmed superior results of Markowitz model in almost every case, especially if serious estimation errors have occurred.

Thus, each of these studies, as well as many other made on a comparison of two mentioned portfolio selection procedures, is focused on specific set of presumptions which rarely lead to general recommendations. Based on the analysis of mentioned papers, the results of Michaud and Markowitz procedure are usually balanced in case of long-term constrains and highly sensitive to changes in the length of the investment period with the possibility of giving investment advices in different initial situations.

\section{Markowitz optimization model}

Markowitz (1952) developed the portfolio selection theory which almost instantly became the foundation of financial economics in the field of asset management and investment practices. He emphasizes the initial premise of this theory that every investment decision is based on some sort of trade-off. By asking the assumption that a rational investor makes investment decision based on expected return and risk, portfolio is considered to be efficient if the minimum variance, as a measure of risk, is achieved for a given level of expected return or if the maximum of expected return is achieved for a given level of portfolio variance. Therefore, the objective of this optimization is to found a portfolio with diversified risk without making any reduction in expected returns.

Also, mentioned author derived the critical line algorithm which identifies all feasible portfolios for a given set of financial instruments with minimizing the risk for a determined level of expected return or maximizing the expected return for a given level of risk. The process of derivation of the efficiency frontier is possible only with the knowledge of three variables: expected return, 
standard deviation and covariance of a set of financial instruments. Graphically presented, the efficiency frontier directly demonstrates the utility of diversification. The size of this utility, ceteris paribus, reflected directly through the value of covariance coefficient and whether the covariance coefficient is lower the degree of diversification is higher and vice versa. Therefore, the efficiency frontier indicates the importance of risk reduction process. The portfolio selection theory expands techniques of linear programming by developing the critical line algorithm initialized from the above mentioned assumptions that investment decisions depends only on expected return $E\left(R_{p}\right)$ and variance $\sigma_{p}^{2}$. Following this background, the procedure of portfolio optimization requires data about $E\left(R_{i}\right)$, as the expected return of the $\mathrm{i}$-th financial instrument, $\sigma_{i}$ as the standard deviation of returns of the i-th financial instrument, $\rho_{i j}$ as the correlation coefficient between returns of two $\mathrm{i}$-th and $\mathrm{j}$-th financial instruments where $i, j=1,2, \ldots, n$ and $\sigma_{i j}$ as the covariance of those two instruments. Consequently, the traditional optimization model or MeanVariance $\mathrm{M}-\mathrm{V}$ model is presented as follows:

$$
\begin{array}{cl}
\text { Min } \quad \sum_{i=1}^{n} \sum_{j=1}^{n} \sigma_{i j} x_{i} x_{j} & \\
\text { st } \quad \sum_{i=1}^{n} E\left(R_{i}\right) x_{i} \geq M \\
\sum_{i=1}^{n} x_{i}=1 \\
x_{i} \geq 0 \quad i=1, \ldots, n
\end{array}
$$

The formulation given by term (1) represents the convex problem of quadratic programming where $\mathrm{M}$ denotes required level of portfolio returns for assumed level of risk, while the $x_{i}$ signifies a percentage of available capital to be invested in the i-th financial instrument. The initial inputs can be distinguished from the aspect of time varying, as daily, monthly, yearly indicators, but also from the aspect of applied estimation model, for example the capital asset pricing model or the arbitrage pricing theory model.

As pointed out by Kirzner (2000), the optimization model formed by the rules mentioned above represents the analysis of the ratio between return and risk which together with the capital asset pricing model makes the modern portfolio theory.

The Mean-Variance model has several obvious disadvantages. The first noticeable criticism of this model is related with the initial assumptions. It is 
generally known that returns are not normally distributed. The investors can derived a different utility function from the initial quadratic form. Besides, investors should have a few investment periods opposite to the one set by the above optimization model. In addition, the risk measure used in optimization model can be regarded as an unacceptable, because it is identical to the way how the values are measured above and below the average return in investment period, while from the investment point of view the variability above the average return is not considered as a risk. Only returns below the average or some predetermined level of return are considered as a relevant measure of risk. In support of this claim is the assumption of return distribution symmetry of well diversified portfolio which is increasingly moving away from the initial point with the growth of the length of the investment period. However, in many conducted researches the efficiency frontier based on variance, as a measure of risk, has very little difference in results with respect to the results of efficiency frontier based on other measures of risk. This still justifies the variance as a suitable measure of risk.

According to Michaud (1998), the most serious problems of Mean-Variance model in practice are instability of estimates and lack of clarity (ambiguity). First of all, these epithets are specific to the Markowitz model due to the fact that even small changes in inputs can lead to strong movements in the weights of individual investments in the optimal portfolio. Therefore, the utility value of this model for the purpose of forming an investment decision is highly questionable.

\section{Bootstrap optimization model}

The main question is why is necessary to apply the resampled efficiency method? Thus, the initial point in explanation of this question is a well-known set of rigid assumption used in a framework of Markowitz optimization model. In practice, the utility function becomes much more complex and involving preferences beyond the range of return/risk ratio. Traditional solutions of this optimization model are static by nature and rely only on the stability of input data. Therefore, stated methodology offers an optimization in just one moment of time, while any minor shift of rigid assumptions or input data could cause serious disturbance in initial solutions. All the above mentioned facts increase estimation errors that conclusively lead to reduction of portfolio selection model utility value.

To avoid those disadvantages, the portfolio selection algorithm featured by dynamic structure has to be installed. Actually, application of bootstrap in portfolio optimization, according to Srivatsa et al. (2010), almost instantly leads to advantages by ignoring the limits of historical data about returns, but at the same time focusing on the range of possible outcomes. In addition, Delcourt and 
Petitjean (2011) elaborate that low diversification rate and sudden shifts in portfolio allocation represent undesirable feature of traditional portfolio selection model and emphasize the need to create an alternative portfolio forming approach. Hence, the resampled efficiency technique is proposed in order to overcome the shortcomings of traditional portfolio selecting procedure. Michaud (1999) patented the resampled efficiency method maintaining certain presumptions of traditional model. According to Becker et al. (2009), the goal of this selection methodology is minimization of risk assessment on portfolio composition, achievement of a higher level of balance in capital allocation and improvement of portfolio performances comparing with initial portfolio model. Scherer (2002) briefly summarizes the most important iterations of resampled efficiency in fallowing manner:

- Estimate variance - covariance matrix and expected return vector of historical inputs

- Resample from original time series inputs by taking B draws from input distribution (this paper uses already mentioned set of bootstrap procedures). At the same time, the number of draws reflects the degree of uncertainty in the inputs. Then, calculate variance - covariance matrix from resampled series.

- Calculate efficient frontier for inputs derived in previous iteration and save optimal portfolio weights for $m$ equally distributed return points along the frontier.

- Repeat previous two steps many times and calculate average portfolio weights for each return point.

Repeating the expected return time series structure, bootstrap procedure insinuate the appearance of different output solutions exact opposite to the standard portfolio selection procedure. On the other hand, considering the ability of showing a wide range of possible optimization solutions, the portfolio derived from bootstrap procedure has desirable characteristics for the investors with different preferences. Such an approach presents an efficient way of visualization of estimation errors made by traditional portfolio optimization procedure. Estimated parameters, using classical optimization model, are calculated on the basis of only one possible return realization in previous period of time. Even though this is an example of stationary process, it can be assumed that only big samples are able to estimate return and risk parameters approximately equal to the real parameter distribution. This is the reason why the proposed resampled efficiency method successfully obtains the random walk of return input data. Furthermore, based on the allegation of related papers, the results of traditional method are highly concentrated, or insufficiently diversified, so the most of available investments are not part of optimal solution. On the contrary, the bootstrap algorithm used in portfolio optimization procedure interprets the weight vector as a set of statistically equal weights whose average offers a final solution in capital allocation process. After 
all, only the original set of weights is the optimal one, while the other options, even bootstrap, are placed bellow efficient frontier. However, their weights are direct result of estimation errors made by resampled procedure.

For a better understanding of the resampled optimization model, further text offers an explanation of new data generating process using two block bootstrap methods.

\subsection{Moving block bootstrap}

In separate papers Kunsch (1989) and Liu and Singh (1992) formulate a new sample construction process called the moving block bootstrap (MBB) or non-overlapping block bootstrap. This method does resampling procedure only within consecutively formed blocks of original data. As the result of such a procedure, the time series structure of original data remains unchanged within every single block of data.

Based on randomly formed samples $X_{1}, X_{2}, \ldots, X_{n}$ an estimation using moving block bootstrap method is defined. If one starts from the assumption that $l \equiv l_{n} \in[1, n]$ is integer, for dependent data is usually requiring to $l \rightarrow \infty$ and $n^{-1} l \rightarrow 0$ when $n \rightarrow \infty$. Anyway, specific description of this bootstrap method has to start from appropriate constrains on the block length $l$. If $B_{i}=\left(X_{i}, \ldots, X_{i+l-1}\right)$ is the ith block in time series, then the block length goes from $X_{i}$ for $1 \leq i \leq N$, where $N=n-l+1$ represents the number of blocks within bootstrap sample. In order to form the sample from presented bootstrap methodology it is necessary to select by random procedure a number of blocks from the set $\left\{B_{1}, \ldots, B_{N}\right\}$. Consequently, $B_{1}^{*}, \ldots, B_{k}^{*}$ indicates a randomly chosen sample with replications from the set $\left\{B_{1}, \ldots, B_{N}\right\}$ where each block contains the same amount of elements $l$. Since the observations within the block $B_{i}^{*}$ are presented as $\left(X_{(i-1) l+1}^{*}, \ldots, X_{i l}^{*}\right)$, where $i=1, \ldots, k$, the bootstrap observations construct the sample $X_{1}^{*}, \ldots, X_{m}^{*}$ based on the moving block bootstrap procedure of size $m \equiv k l$.

\subsection{Stationary block bootstrap}

Similar to the previous bootstrap procedure, the stationary bootstrap, created by Politis and Romano (1994), involves sampling with replication of original data in order to form new pseudo samples of initial time series and to repeat the statistical estimation of interest, but with a crucial difference in terms of time series stationary process. The mentioned bootstrap is generally applicable in case of stationary time series with low data dependences. New 
formed samples of time series made by some block bootstrap process are not stationary, so the stationary bootstrap algorithm is used to remove this unwanted statistical feature. Namely, according to original data sample $X_{1}, X_{2}, \ldots, X_{n}$ one generates pseudo time series $X_{1}^{*}, X_{2}^{*}, \ldots, X_{n}^{*}$ through an adequate scheme of repeatedly forming samples that are really stationary. The procedure defined in such a manner is trying to simulate the characteristics of the original sample by keeping the time series stationarity within pseudo samples. To achieve desirable statistical results, one suggests the application of bootstrap process based on random block length pattern.

\section{Investment portfolio performances}

With attention to test performances of two mentioned investment portfolio optimization model, the efficiency analysis in further text performs a process based on two iterations. In first, the real values of coefficients of returns, variances and covariances are calculated, while the second iteration considers the derivation of possible coefficient outcomes for a predefined period of observation from the bootstrap distribution of parameters of interest. Nevertheless, the second iteration indicates some sort of approximation of optimization process that corresponds to potential shifts in input parameters.

The vector of expected returns $\mu$ and the variance-covariance matrix $\underline{\Sigma}$ are calculated from selected bootstrap distribution. The estimation process of mentioned parameters repeats B times for each initial optimization strategy.

Than, the optimization is performed by resampling and obtained results are compared with the traditional optimization results. Investment portfolio alternatives are realized only under the assumptions of risk-free loans for investment capital shortages and case of "no constraints" or long-only constraints. The long-only constraint considers no selling of the assets in which we invest capital during the observed time horizon. Both constraints imply that the weights of individual investments in portfolio are within $0 \leq x_{i} \leq 1$. As the results, the optimal portfolio weights for each implemented optimization approach are obtained.

In order to successfully assess and compare the performances of presented optimization processes, Becker et al. (2009) suggest the estimation measure of investment performance values $\phi$, which is obtained by the following matrix equation:

$$
\phi=\underline{x}^{T} \cdot \underline{\mu}-\frac{\lambda}{2} \cdot \underline{x}^{T} \cdot \underline{\Sigma} \cdot \underline{x}
$$


Where $\underline{x}$ represents the vector of weights of $\mathrm{n}$ individual risky investments in portfolio, and $\lambda$ is the risk aversion coefficient. If we start from the assumption of returns normal distribution, the results of the preference function $\phi$ are equivalent to the utility function returns if risk aversion coefficient remains constant.

Except the preference function, this paper uses the Sharpe ratio in process of optimization strategies comparison. The ratio shows the measure of risk premium per unit of investment returns standard deviation and it can be presented as follows:

$$
S=\frac{E\left(R_{p}\right)-E\left(R_{B}\right)}{\sigma_{p}}
$$

Where $E\left(R_{p}\right)$ is expected portfolio return, $E\left(R_{B}\right)$ is expected return of benchmark investment, usually risk-free investment or some predefined return on investment, and $\sigma_{p}$ is standard deviation of mentioned portfolio investment.

This indicator proves how good the investments return rate compensates the level of assumed risk.

\section{Empirical analysis}

For the purpose of portfolio optimization, this paper includes daily data of prices and returns derived from the prices of the most frequently traded stock on the Belgrade Stock Exchange (NIIS - NIS Novi Sad ${ }^{2}$, AIKB - AIK banka Niš ${ }^{3}$, KMBN - Komercijalna banka Beograd ${ }^{4}$, ENHL - Energoprojekt holding Beograd $^{5}$, SJPT - Soja protein Bečej ${ }^{6}$, IMLK - Imlek Boegrad ${ }^{7}$, FITO Galenika Fitofarmacija Zemun ${ }^{8}$, MTLC - Metalac Gornji Milanovac ${ }^{9}$, GMON Goša montaža Velika Plana ${ }^{10}$ ) in five years period of time or more precisely from October 2008 to October 2013. Therefore, the initial sample encompasses 1250 daily observations. This period of time was mainly characterized by the average upward stock price trend on financial market. In table 1 are presented expected returns and standard deviations of stocks in three investment periods.

\footnotetext{
${ }^{2} \mathrm{http} / / /$ www.belex.rs/trgovanje/hartija/dnevni/NIIS

${ }^{3} \mathrm{http}: / /$ www.belex.rs/trgovanje/hartija/dnevni/AIKB

${ }^{4} \mathrm{http}: / /$ www.belex.rs/trgovanje/hartija/dnevni/KMBN

${ }^{5} \mathrm{http}: / /$ www.belex.rs/trgovanje/hartija/dnevni/ENHL

${ }^{6} \mathrm{http}: / /$ www.belex.rs/trgovanje/hartija/dnevni/SJPT

${ }^{7} \mathrm{http}: / /$ www.belex.rs/trgovanje/hartija/dnevni/IMLK

${ }^{8} \mathrm{http}: / /$ www.belex.rs/trgovanje/hartija/dnevni/FITO

${ }^{9} \mathrm{http} / / /$ www.belex.rs/trgovanje/hartija/dnevni/MTLC

${ }^{10} \mathrm{http} / / /$ www.belex.rs/trgovanje/hartija/dnevni/GMON
} 
Table 1 Expected returns and standard deviations of individual stocks in different investment periods

\begin{tabular}{|c|c|c|c|c|c|c||}
\hline \multirow{2}{*}{ Akcija } & \multicolumn{3}{|c|}{$\mathrm{E}\left(\mathrm{R}_{\mathrm{i}}\right)$} & \multicolumn{3}{c||}{$\sigma_{\mathrm{i}}$} \\
\cline { 2 - 7 } & $\mathrm{T}=250$ & $\mathrm{~T}=750$ & $\mathrm{~T}=1250$ & $\mathrm{~T}=250$ & $\mathrm{~T}=750$ & $\mathrm{~T}=1250$ \\
\hline NIIS & 0.0231 & 0.0178 & 0.0117 & 0.0100 & 0.0180 & 0.0132 \\
\hline AIKB & 0.0041 & -0.0166 & 0.0013 & 0.0190 & 0.0241 & 0.0230 \\
\hline KMBN & -0.0009 & -0.0151 & 0.0009 & 0.0258 & 0.0234 & 0.0253 \\
\hline ENHL & 0.0366 & -0.0056 & 0.0107 & 0.0206 & 0.0229 & 0.0228 \\
\hline SJPT & 0.0230 & 0.0007 & 0.0037 & 0.0272 & 0.0254 & 0.0227 \\
\hline IMLK & 0.0233 & 0.0218 & 0.0224 & 0.0233 & 0.0218 & 0.0236 \\
\hline FITO & 0.0290 & 0.0008 & 0.0155 & 0.0237 & 0.0276 & 0.0263 \\
\hline MTLC & 0.0221 & 0.0054 & 0.0093 & 0.0132 & 0.0145 & 0.0176 \\
\hline GMON & 0.0130 & 0.0051 & 0.0048 & 0.0333 & 0.0329 & 0.0367 \\
\hline \hline
\end{tabular}

Source: Authors` research

\subsection{Investment portfolio optimization}

The process of forming investment portfolio starts with selection of stock set of appropriate investment potential. For the purpose of this research, nine before mentioned regular stocks from domestic financial market are considered. While each stock has equal chances to take a part in final investment portfolio. Respecting all stated assumptions, the resume of this paper represents an empirical simulation study of forming a sequence of different investment combinations according to risk/return ratio and advantages/disadvantages of traditional and resampled optimization process.

In defining criterion function, the required monthly rate of return $\mathrm{M}$ is assigned from $0 \%, 0.1 \%$ to $2.2 \%$. This set of 23 ranks of returns is determining the level of accepted risk by using the algorithm of quadratic programming (1). Therefore, the combinations of required returns and accepted risks are forming the efficiency frontier. In search for the best risk/return ratio, the problem of adequate capital allocation emerges as the one of the most important segment of investment strategy. The weights of invested capital in certain stock $x_{i}$ became variables with different level of requested return. Consequently, Figure 1 shows the proportion of invested capital in each individual stock according to the ranks of required returns and based on the problem of quadratic programming (1).

The usage of the classical Markowitz optimization model with weight results for each stock in investment portfolio, presented in Figure 1, emphasizes the presence of the low diversification level among nine observed stocks in the portfolio. By varying the required rate of return, Figure 1 displays only three stocks that appear in the portfolio at the same time. 
Figure 1 Allocation of available capital using standard deviation as the criterion function

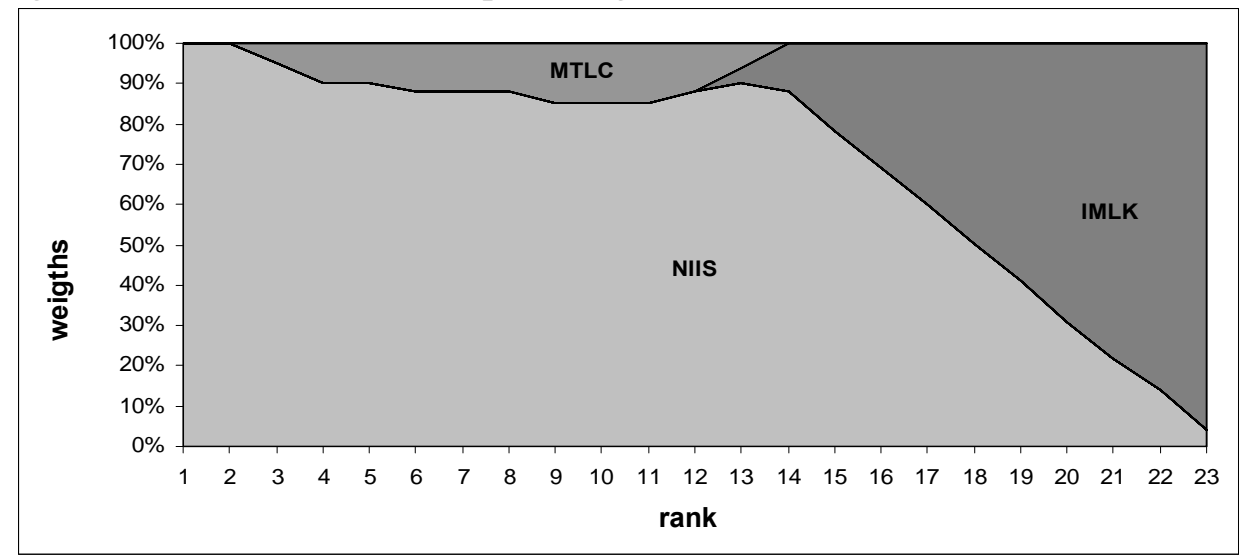

Source: Author's research

On the other hand, the number of realizations of time series stochastic process, made by using bootstrap procedures, contributes to the stability of optimization model estimations. Actually, such a process of optimization creates an adequate base for a dynamic approach of scanning the stock price return movements and avoiding the decision process made by the statement in one period of time. Besides, such a process creates conditions for the higher level of diversification presented in Figures 2 and 3.

Figure 2 Allocation of available capital using the moving block bootstrap in portfolio optimization

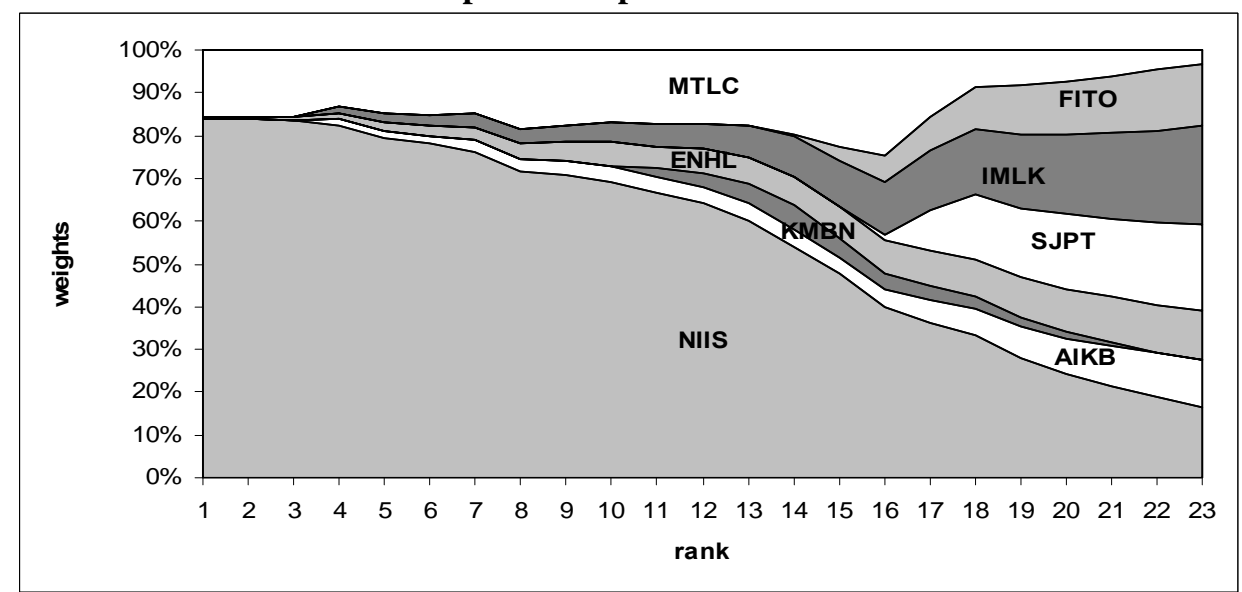

Source: Author's research

Comparing Figure 1 with other two we noticed a significant percentage difference available capital allocation. Also, offered bootstrap solutions give a 
much smoother transition of single stock weights in investment portfolio along the efficiency frontier. Such diversification, with low level of statistical error, provides higher investment performances in and out of sample unlike the classical optimization model which keeps the high level of errors in formed sample. The differences between these two optimization models are mainly the consequence of historical variance. There is a high probability of big differences among numerous scenarios made by simulation process. Therefore, it is necessary to execute a detail analysis of marginal ratios between required returns and acceptable level of risk in case of bootstrap and $\mathrm{M}-\mathrm{V}$ optimization model. However, some differences are noticeable even between used bootstrap methods according to the differences in initial bootstrap algorithms. Anyway, all bootstrap procedures are followed by the unique pattern weight movements in line with the required level of return.

Figure 3 Allocation of available capital using the stationary block bootstrap in portfolio optimization

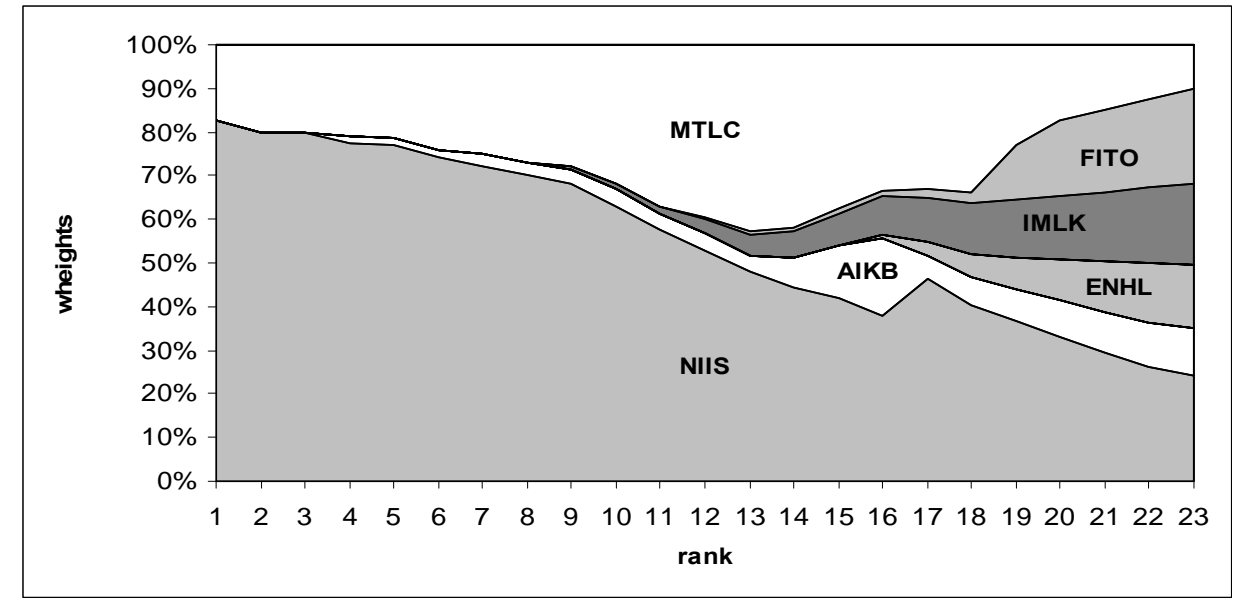

Source: Author's research

\subsection{The efficiency frontiers}

The efficiency frontier represents the initial point in investigating the quality of formed investment portfolio. The frontier indicates the set of the best investment solutions considering the ratio between required return and acceptable risk. At the beginning, the classical $\mathrm{M}-\mathrm{V}$ efficiency frontier is calculated using the original data set of financial time series and it emphasize that only weights calculated by the Markowitz model give the optimal solution according to original set of data. The analysis continues with resampling procedure applying two separate bootstrap methods in process of optimization. After that, the graphical presentation of mentioned models is presented in Figure 4. 
Figure 4. $M-V$ and resampled efficiency frontiers

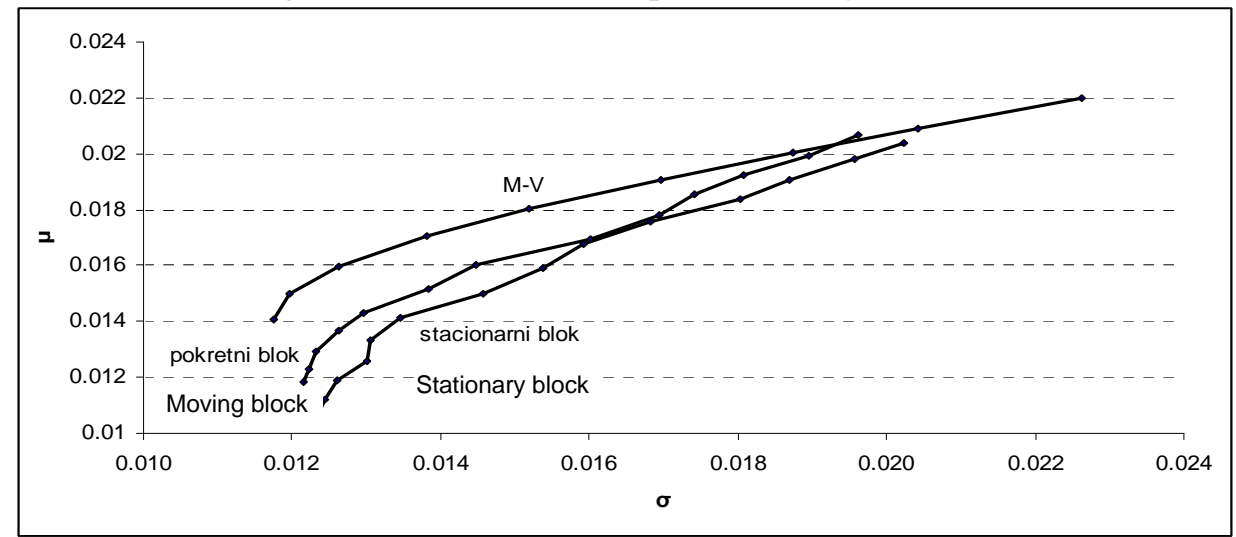

Source: Author's research

Figure 4 shows that the most of the possible combinations of return and risk for different variants of resampled investment portfolios are below original $\mathrm{M}$ $\mathrm{V}$ efficiency frontier, which once again confirms the fact that only optimum from the classical optimization model are considered as the real optimum based on the original set of data. However, in favor of more frequent use of resampled procedures stands the greater number of securities in formed efficient portfolios and not so obvious shifts in capital allocation according to level of required return. These two features are considered as desirable in investment decision making process.

\subsection{Testing investment portfolio performances}

Previously made comparison of classical optimization models and resampled models delivers a lot about their features and possible situations for efficient application. However, significant differences, given by preceding research, open numerous questions and increase stake in testing investment portfolio results. Diversification encourages a better relation of yielded return per unit of risk, while not enough diversified portfolio brings low level of investment performances out of sample. Such hypotheses are not fully confirmed and mainly depend on case by case, which open a question about appropriate testing. In case of uncontrolled, non-standardized tests desirable results are mostly absent, so there is a need for continuous controlling of the investment in and out of sample in order to be completely prepared for eventual reallocation of invested capital.

At the beginning, in sample testing is performed by using the estimation measure of investment performance values and the Sharpe ratio. On that occasion, $\lambda=1$ have been chosen for testing sensitivity of the risk aversion coefficient. 
Table 2 In sample investment portofolio performances

\begin{tabular}{|c|c|c|c|c|}
\hline \hline Required return & $\begin{array}{c}\text { Performance } \\
\text { measure }\end{array}$ & M-V model & $\begin{array}{c}\text { Moving } \\
\text { block }\end{array}$ & $\begin{array}{c}\text { Stationary } \\
\text { block }\end{array}$ \\
\hline \multirow{2}{*}{$0.5 \%$} & $\phi$ & 0.00545 & 0.00364 & 0.00291 \\
\cline { 2 - 5 } & $\mathrm{S}$ & 0.96547 & 0.85441 & 0.78956 \\
\hline \multirow{2}{*}{$1 \%$} & $\phi$ & 0.00543 & 0.00554 & 0.00506 \\
\cline { 2 - 5 } & $\mathrm{S}$ & 0.99621 & 0.98854 & 0.91205 \\
\hline \multirow{2}{*}{$1.5 \%$} & $\phi$ & 0.00922 & 0.00901 & 0.00825 \\
\cline { 2 - 5 } & $\mathrm{S}$ & 1.22104 & 1.11458 & 1.06325 \\
\hline \multirow{2}{*}{$2 \%$} & $\phi$ & 0.01054 & 0.01047 & 0.00996 \\
\cline { 2 - 5 } & $\mathrm{S}$ & 1.05698 & 1.06657 & 1.03215 \\
\hline
\end{tabular}

Source: Author's research

The results of two investment performance measures given in Table 2 shows that bootstrap methods follow $\mathrm{M}-\mathrm{V}$ model in results, especially in case of higher level of required returns.

Concerning the effects of diversification in invested portfolio based on some bootstrap optimization method, it is necessary to conduct similar analysis out of sample. This paper involves six month period from October 2013 to March 2014, or accurately 104 daily observations of mentioned stock price returns. Therefore, the performance results depend on estimated weights of each stock for required returns in the formed sample, but also on expected returns, variances and covariances out of the sample.

Table 3 Out of sample investment portfolio performances

\begin{tabular}{||c|c|c|c|c|}
\hline Required return & $\begin{array}{c}\text { Performance } \\
\text { measure }\end{array}$ & M-V model & $\begin{array}{c}\text { Moving } \\
\text { block }\end{array}$ & $\begin{array}{c}\text { Stationary } \\
\text { block }\end{array}$ \\
\hline \multirow{2}{*}{$0.5 \%$} & $\phi$ & 0.00122 & 0.00143 & 0.00131 \\
\cline { 2 - 5 } & $\mathrm{S}$ & 0.22254 & 0.24044 & 0.23699 \\
\hline \multirow{2}{*}{$1 \%$} & $\phi$ & 0.00122 & 0.00131 & 0.00142 \\
\cline { 2 - 5 } & $\mathrm{S}$ & 0.22607 & 0.25023 & 0.23229 \\
\hline \multirow{2}{*}{$1.5 \%$} & $\phi$ & 0.00182 & 0.00165 & 0.00212 \\
\cline { 2 - 5 } & $\mathrm{S}$ & 0.26395 & 0.27771 & 0.34006 \\
\hline \multirow{2}{*}{$2 \%$} & $\phi$ & 0.00178 & 0.00291 & 0.00194 \\
\cline { 2 - 5 } & $\mathrm{S}$ & 0.21458 & 0.41008 & 0.32907 \\
\hline
\end{tabular}

Source: Author's research

Increasing the level of diversification and its influence on decrease of the formed portfolio variance produces certain level of improvement in case of the 
out of sample investment performances, as one can see in Table 3. Nevertheless, it should be emphasize that this is only one subsample created outside of the initial estimation period, so the results have to be considered with certain care and caution.

\subsection{Testing portfolio sensitivity for investment period length}

Considering the assumption of return time series stationarity, each extension of the initial sample potentially decreases the estimation errors, i.e. they converges to 0 when number of included observations tends to infinity. According to Choi and Mukherji (2010), supporters of time investment portfolio diversifications suggest a decrease of stock return volatility when comes to a certain increase of included observations. Cogneau and Zakamouline (2010) accept the fact that time period is one of the crucial in defining an optimal portfolio allocation. Hickman et al. (2001) noticed that in long term investors achieve much lower marginal returns if they not invest in risky assets. Risk-free or low risk investment brings lower rate of performances in long run then some portfolios made of several risky investments.

With difficulties in collecting an adequate historical time series of returns, including estimations of total risk and expected return of portfolio, particularly in case of highly volatile financial markets in developing countries, Hansson and Persson (2000) and Cogneau and Zakamouline (2010) introduce series of resampled returns from available data set. Retaining the length of initial sample and respecting the trends before and after the global economic crises that could lead to wrong directions in optimization model realizations, this paper stays within the timeframe suggesting bootstrap procedure to overcome some lack in predictive power of the initial sample. In this sense, this paper involves short, medium and long time period of investment, i.e. the samples that contains one, three and five years of daily returns, as presented in Table 1.

The previously mentioned Table 1 does not indicate only increase of expected return and standard deviation with the increase in the time horizon. However, pronounced changes in expected returns than in standard deviations decrease the portfolio weights of stocks with lower levels of standard deviations and increase the weights of stocks with higher levels of expected returns, as the time interval increases. Consequently, the shifts in investment time intervals affect the changes in capital allocation. In other words, possible change in decision within investment period emphasizes the need of revising weights of each stock involved in invested portfolio. Therefore, each time interval and optimization model has its own portfolio weights including its own measures of performances, presented in the next table. 
Table 4 Investment portfolio performances in different time periods

\begin{tabular}{|c|c|c|c|c|c|c||}
\hline \multirow{2}{*}{$\begin{array}{c}\text { Optimization } \\
\text { method }\end{array}$} & \multicolumn{3}{|c|}{ Sharpe ratio } & \multicolumn{3}{c||}{$\phi$} \\
\cline { 2 - 7 } & $\mathrm{T}=250$ & $\mathrm{~T}=750$ & $\mathrm{~T}=1250$ & $\mathrm{~T}=250$ & $\mathrm{~T}=750$ & $\mathrm{~T}=1250$ \\
\hline $\mathrm{M}-\mathrm{V}$ model & 0.2398 & 0.1965 & 0.2321 & 0.0239 & 0.0182 & 0.0222 \\
\hline Moving block & 0.2875 & 0.2844 & 0.2898 & 0.0212 & 0.0227 & 0.0224 \\
\hline Stationary block & 0.2571 & 0.2590 & 0.2476 & 0.0217 & 0.0232 & 0.0209 \\
\hline
\end{tabular}

Source: Author's research

Given results of the performance measures using classical optimization model open a question about efficient application of the method in decision making process. Actually, stated differences in results of this method refer to emphatic estimation errors and need for given optimum reviews with every significant change in expected return. On the other hand, bootstrap procedures, with their finite number of replication of possible scenario based on historical time series, dedicate more attention to risky assets which, by the rule, carry higher levels of expected returns and at the same time by the more efficient diversification maintain the level or risk relatively low. Hence the performances mainly increase with the growth of observations involved in the optimization model. Also, the high level of results stability without sudden shifts is present, which mostly speaks about unbiased and efficient estimation of the bootstrap optimization model. In other words, bootstrap methods offer investment performances that are considerably robust than results of the classical optimization model, i.e. this methods decrease the level of performance sensitivity involving shifts in investment periods.

\section{Conclusion}

Creating investment portfolio by resampling procedure offers an intuitive way of facing with sample errors during investment portfolio optimization. The process of sample replication characteristic for the resampled efficiency method helps in measuring uncertainty effects in investment environment. Comparing the $\mathrm{M}-\mathrm{V}$ optimization model and bootstrap optimization models, one gets a strong impression that bootstrap methods lead to more stabile estimation of investment portfolio with a higher rate of diversification.

However, when comes to a question about performance measures, this paper does not fully succeed in proving that bootstrap methods overcome classical optimization model in sample. Anyway, considering the investment performances out of sample, as well as sensitivity testing of the performances in changing periods of investment, it is plausible to give positive observations in favor of bootstrap methodology. Including a large number of random scenarios through bootstrap procedure gives estimation less sensitive to changes in input factors of uncertainty and the length of investment period. 


\section{References}

Becker, F., Gürtler, M., Hibbeln, M. (2009). Markowitz versus Michaud: Portfolio Optimization Strategies Reconsidered, preuzeto 22.10.2013. sa sajta: http://econstor.eu/bitstream/10419/55254/1/684929953.pdf

Black, F., Litterman, R. (1992) "Global Portfolio Optimization", Financial Analysts Journal, 48(5): 28-43.

Choi, B.P., Mukherji, S. (2010) "Optimal Portfolios for Different Holding Periods", Journal of Business \& Economics Research, 8(10): 1-6.

Cogneau, P., Zakomouline, V. (2010) Bootstrap Methods for Finance: Review and Analysis, preuzeto 27. decembra 2011. sa sajta: http://www.seminar.hec.ulg.ac.be/docs/Sem21.10.10_Cogneau.pdf

Delcourt, F., Petitjean, M. (2011) "To What Extent is Resampling Useful in Portfolio Management", Applied Economic Letters, 18(3): 239-244.

Fama, E., French, K. (1988) "Permanent and Temporary Components of Stock Prices“, Journal of Political Economy, 96(2): 246-273.

Fletcher, J., Hillier, J. (2001) "An Examination of Resampled Portfolio Efficiency“, Financial Analysts Journal, 57(5): 66-74.

Hansson, B., Persson, M. (2000) "Time Diversification and Estimation Risk", Financial Analysts Journal, 56(5): 55-62.

Harvey, C., Liechty, J., Liechty, M. (2008) "Bayes vs. Resampling: A Rematch", Journal of Investment Management, 6(1): 29-45.

Hickman, K., Hunter, H., Byrd, J., Beck, J., Terpening, W. (2001) "Life Cycle Investing, Holding Periods and Risk“, The Journal of Portfolio Management, 27(2): 101-111.

Kirzner, E. (2000) Fact and Fantasy in Index Investing, Rotman School of Management, University of Toronto.

Künsch, H. (1989) "The Jackknife and the Bootstrap for General Stationary Observations“, Annals of Statistics, 17(3): 1217-1241.

Liu, R., Singh, K. (1992) Moving Blocks Jackknife and Bootstrap Capture Weak Dependance, New York: John Wiley \& Sons.

Markowitz, H. (1952) "Portfolio Selection", The Journal of Finance, 7(1): 77-91.

Markowitz, H., Usmen, N. (2003) "Resampled Frontier Versus Diffuse Bayes: An Experiment", Journal of Investment Management, 1(4): 9-25.

Michaud, R. (1998) Efficient Asset Management: A Practical Guide to Stock Portfolio Optimization and Asset Allocation, Boston: Harvard Business School Press.

Michaud, R., Michaud, R. (2008) Efficient Asset Management: A Practical Guide to Stock Portfolio Optimization and Asset Allocation, $2^{\text {nd }}$ Edition, Oxford University Press.

Politis, D., Romano, J. (1994) "The Stationary Bootstrap", Journal of the American Statistical Association, 89(428): 1303-1313.

Scherer, B. (2002) "Portfolio Resampling: Review and Critique", Financial Analysts Journal, 58(6): 98-109.

Srivatsa, R., Smith, A., Lekander, J. (2010) "Portfolio Optimisation and Bootstrapping", Journal of Property Investment and Finance, 28(1): 24-33. 


\section{TESTIRANJE PERFORMANSI INVESTICIONOG PORTFOLIJA PRIMENOM BLOK BUTSTREP METODA}

Apstrakt: Cilj ovog rada jeste kreiranje stabilnog modela optimizacije investicionog portfolija kroz visok stepen diversifikacije i smanjenje iznenadnih promena u alokaciji sa praćenjem dinamike faktora uticaja. U tom smislu, javlja se primena butstrep procedure, koja bez prevelikog broja uključenih ograničenja u procesu optimizacije pruža rešenja zasnovana na neizvesnim informacijama. Ovako definisan metod optimizacije patentiran je od strane Michauda (1999) pod nazivom reuzorkovana efikasnost. Prema tome, ovaj rad nudi komparaciju performansi blok butstrep modela optimizacije i tradicionalnog Markowitzevog modela unutar i van uzorka primenjujući najčešće trgovane akcije na Beogradskoj berzi. Rezultati pokazuju bolje performanse izvan uzorka, kao i zastupljenost većeg broja akcija formiranjem portfolija putem butstrep metodologije. Ipak, samo putem tradicionalnog procesa optimizacije se može dostići optimum shodno postavljenim ograničenjima. Takvi efekti se mogu opaziti poređenjem granica efikasnosti dobijenih putem navedenih modela optimizacije. Međutim, optimizacija zasnovana na butstrep metodima svoje mesto pronalazi u smanjenju grešaka ocenjivanja proisteklih iz ograničene veličine uzorka.

Ključne reči: Investicioni portfolio, optimizacija, reuzorkovana efikasnost, butstrep, granica efikasnosti 